\title{
Finite element modeling of bearing elements technological machines and equipment
}

\author{
Sergey I. Yevtushenko*, Sergey A. Alekseev, Igor A. Petrov, and Vladimir E. Fedorchuk \\ Platov South-Russian State Polytechnic University (NPI), 346400 Novocherkassk, Russia
}

\begin{abstract}
The paper considers the examples of technical production tests to determine the bearing capacity of the structural elements of technological machines and equipment used in various industries and agriculture: the bearing beam of the front axle of the combine harvester, fixed support plates of the apparatus for the production of plastic containers, bearing profiles of the thermal press designed to connect the ends of conveyor belts of various sizes, etc. The nature of stress distribution and deformations in the elements of the existing variants of technological machines and equipment allowed to identify shortcomings in their design. Analysis of calculations in ANSYS environment allowed to recommend variants of models of technological machines and equipment with better indicators of bearing capacity. This will greatly improve their reliability and performance.
\end{abstract}

\section{Introduction}

Currently, the production of technological equipment in various industries is associated with the policy of import substitution. New machines and equipment of the domestic production for sale in the domestic market should be controlled according to technical and economic parameters with the analogues of foreign manufacturers, in this regard, reliability issues with simultaneous reduction of production costs remain relevant. One of the ways to solve these problems is to assess the stress-strain state of the process equipment structures.

Currently used software and computer systems that implement the method of compact elements, allow to obtain data in detail on the stress-strain state of the structure as a whole and its individual elements, including the stress concentration zone. In addition, it is possible to take into account the cyclic nature of the loads, leading to a decrease in the metal endurance, especially in the areas of stress concentrators. The data obtained in the calculation allow us to give real estimates of the strength, rigidity and reliability of the structure and make reasonable recommendations that eliminate the influence of negative factors [15].

We used the universal softwaretion system finite element (FEM) analysis and ANSYS $[4,5]$ software package StructureCAD [3, 10].

\footnotetext{
*Corresponding author: evtuhenko s@novoch.ru
} 


\section{Brief description of the methods of calculation}

Preliminary calculations were made by analytical methods and using separate modules of the software-computing complex StructureCAD. The geometric characteristics of the structural elements of complex cross-section configuration were determined using the calculation module "SECTION" of the software-computing StructureCAD. These dimensions were optimized, which allowed to obtain the maximum parameters of the flexural stiffness of the elements, taking into account technological constraints.

Finite element model includes octagonal solid elements.

Glue contact was made between the components at the separation zone of seam welding. In other areas contact mechanics was sold. Bolted joints were modeled by solid elements considering contact zones. The calculation in the bolt connection of the top plate with the main structure was made in view of the preloading of bolts tightening.

The loading was set by pressure on a selected area of the element surface.

Moreover, calculation was carried out taking into account geometrical nonlinearity: each step of loading considered strain state of the structure obtained in the previous step.

The analytical method means that point moment equations are recorded, moments in horizontal and vertical planes are calculated, horizontal and vertical forces and von Mises equivalent stress are estimated for each section, and relies on this data the yield factor can be found $[1,2,13,14]$ :

$$
n_{y}=\frac{\sigma_{y}}{\sigma} \geq[n]
$$

$\sigma_{y}-$ yield stress of the material;

$[n]-$ minimal yield factor, which is 1,5 .

Fatigue safety factor is determined by the following formula:

$$
n=\frac{\sigma_{-1}}{k_{\sigma} \cdot \sigma_{a}+\psi_{\sigma} \cdot \sigma_{y}} \leq 2.0
$$

where

- $\sigma_{-1} \approx 0.4 \cdot \sigma_{y}$,

- $k_{\sigma}$ - fatigue notch factor,

- $\sigma_{a}=\sigma\left(k_{D}-1\right)$ - the amplitude of stress,

- $\psi_{\sigma}$ - stress ratio, 0.1 ,

- $k_{D}$-dynamic factor, 1.2.

\section{Results of stress-strain analysis of structural elements of technological machines and equipment}

As an example, we present the results of finite element modeling of the bearing elements of the process equipment: fixed plates of the power plant for the production of plastic tanks and thermal press for the repair of the conveyor belt.

\subsection{Modeling of fixed plate power plant for the production of plastic containers}

Model 1 (basic) had imperfections (figure 1). They were due to design errors and violations in the manufacture. Based on the analysis of the basic model, several options for design 
solutions were proposed.
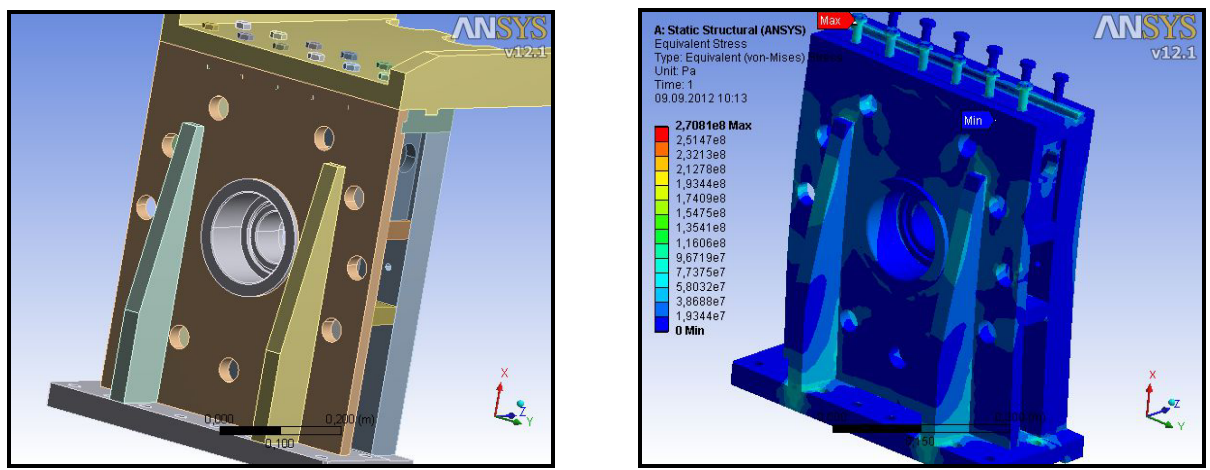

Fig. 1. Model 1 and equivalent von Mises stresses.

One of the solutions (model 3) (figure 2) has better performance than the basic and other models:

- model 3 provides the greatest rigidity;

- it has the simplest manufacturing technology;

- values of stresses are within the limits of permissible values;

- it is devoid of the common drawbacks of previous models.
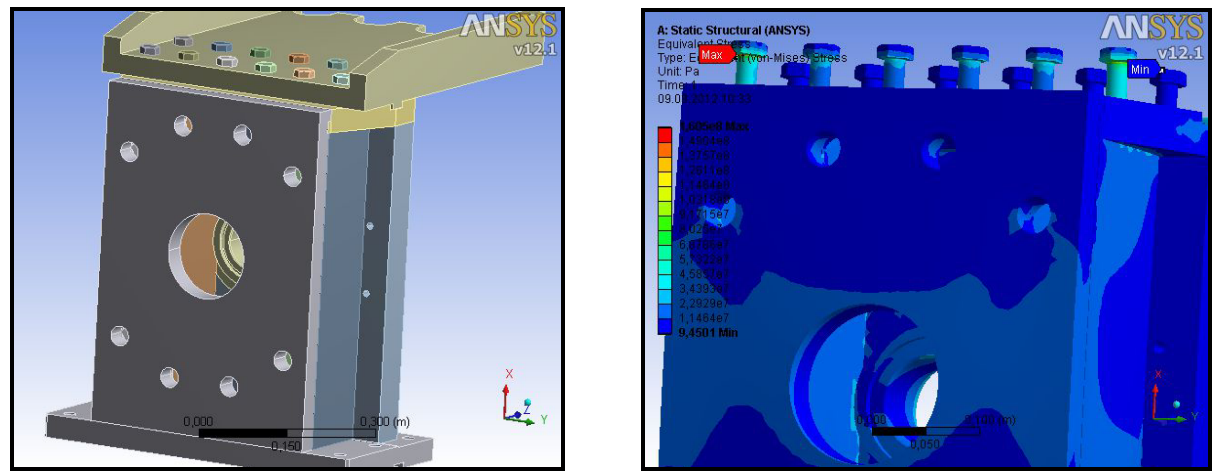

Fig. 2. Model 3 and equivalent von Mises stresses.

Summarized results of the check (strength) analysis of stationary plates of industrialtechnological equipment are shown in table 1.

Table 1. Strength analysis results.

\begin{tabular}{|c|c|c|}
\hline Title & Model № 1 & Model № 3 \\
\hline Number of finite elements & 128391 & 132443 \\
\hline And another entry & 35 & 22 \\
\hline Number of active solid elements & 306.0 & 354.9 \\
\hline Ratio of maximum strains & 1.00 & 0.60 \\
\hline Stress ratio: & 1.00 & 0.59 \\
Von Mises stress & 1.00 & 0.56 \\
Vertical-axis stress & 1.00 & 0.35 \\
Pressure stress &
\end{tabular}




\subsection{Modeling of the bearing element of the thermal press}

The bearing element of the thermal press for the repair of the conveyor belt has a complex cross-section (figure 3). The dimensions of the basic profile of the bearing element have been optimized to increase the stiffness characteristics with the help of the author's calculation program.

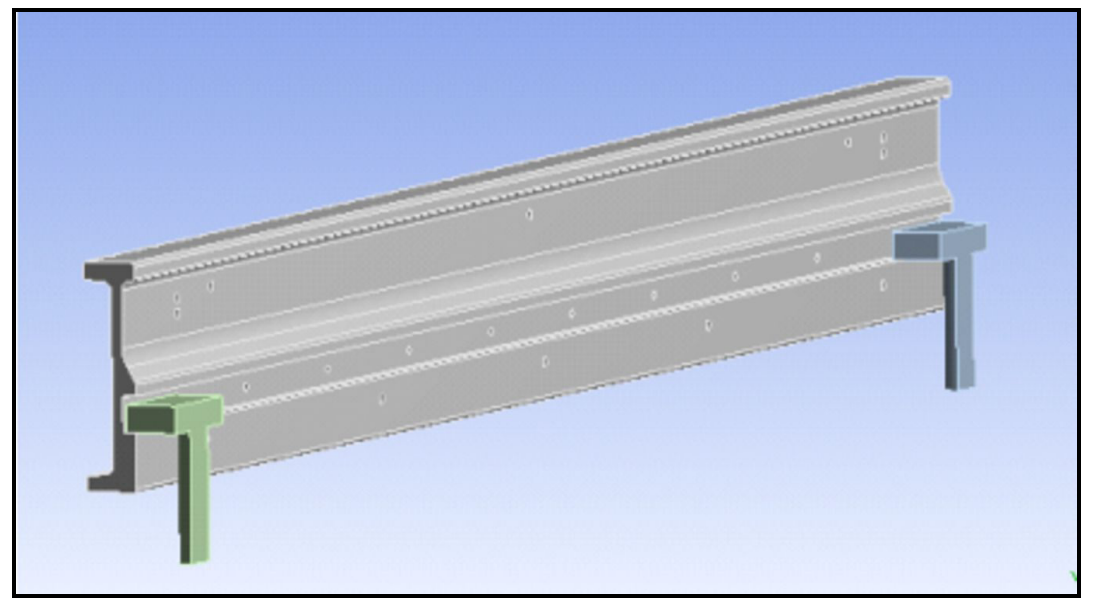

Fig. 3. Model of the bearing element of the thermal press.

The nature of the distribution of stresses are shown in figure 4 .

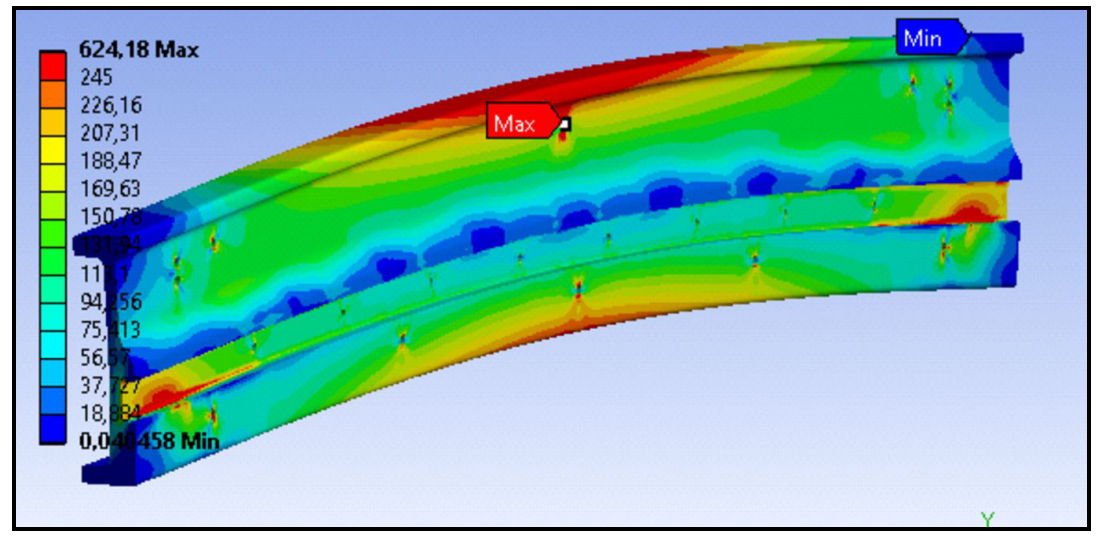

Fig. 4. Graphical representation of fields of equivalent stresses on a deformed model.

\section{Conclusions}

The analysis of the results of studies of the stress-strain state of the elements of technological machines and equipment allowed to draw conclusions:

- software and computer systems that implement the finite element method allow to obtain data in detail on the stress-strain state of the structure as a whole and its individual elements, including zones of concentration of stresses;

- it is possible to take into account the cyclic nature of the load, which leads to a decrease in the endurance of the metal, especially in the areas of stress concentrators; 
- the data obtained in the calculation allow us to give real estimates of the strength, stiffness and reliability of the structure and make reasonable recommendations that eliminate the influence of negative factors;

- finite element analysis more allows-to perform a visual check of locations and sizes of areas with critical stresses;

- finite element modeling gives a close definition of the fatigue safety factor.

\section{References}

1. SP 20.13330.2016 "Loads and actions" (The updated edition of the SNiP 2.01.07-85*).

2. SP 128.13330.2016 "Aluminum construction" (The updated edition of the SNiP 2.03.06-85).

3. V.S. Karpilovskiy, E.Z. Kriksunov, A.A. Malyarenko, M.A. Mikitarenko, A.V. Perelmuter, M.A. Perelmuter, Vychislitelnyy kompleks SCAD [Computer complex SCAD] (SKAD SOFT, Moscow, 2009)

4. N.N. Fedorova, S.A.Valger, M.N. Danilov, Y.V. Zakharova, Basics of working in Ansys 17 (DMK, Moscow, 2017)

5. K.A. Basov, Ansys for engineers (DMK Press, Moscow, 2016)

6. Y.A. Sagdeev, S. P. Kopysov, A. K. Novikov, Introduction to finite element method, 44 (2011)

7. V.A. Ovcharenko, Calculation of problems of mechanical engineering with finite element method (DSMA, Kramatorsk, 2004)

8. V.P. Agapov, The finite element method in statics, dynamics and stability of structures, 2nd edition (DIA, Moscow, 2004).

9. N.A. Alfutov, Stability of Elastic Structures (New Yoork, 2000)

10. V.S. Karpilovskaya, E.Z. Kriksunov, A.A. Malyarenko, M.A. Mikitarenko, A.V. Perel'muter, M.A. Perel'muter, SCAD OFFICE. The computing complex SCAD (Publishing house of Association building universities, Moscow, 2004)

11. V.I. Feodosiev, Advanced Stress and Stability Analysis (New York, 2005)

12. N.N. Shaposhnikov, Calculation of the bending plate finite element (Proceedings of the MSRT, 1968)

13. S.I. Evtushenko, M.N. Shutova, L.V. Shkurakov, I.A. Petrov and V.E. Fedorchuk, The expertise of strength calculation of the guiding axle beam Int. Conf. on Engineering (Rostov-on-Don: Rostov State University of Civil Engineering), 56 (2008)

14. S.I. Evtushenko, I.A. Petrov, M.N. Shutova, A.S. Alekseeva, IOP Conf. Series: Materials Science and Engineering, 177, 012023 (2017)

15. S.I. Evtushenko, I.A. Petrov, S.A. Alekseev, A.S. Alekseeva, International Conference on Industrial Engineering, Applications and Manufacturing (ICIEAM), doi: 10.1109/ICIEAM.2017.8076433 (2017) 